Office of Public Health Studies, University of Hawaii at Manoa, Honolulu, HI, USA cmpirkle@hawaii.edu Cite this as: BMJ2020;370:m3510 http://dx.doi.org/10.1136/bmj.m3510 Published: 9 September 2020

\title{
Evidence based care for pregnant women with covid-19
}

\section{Still a work in progress \\ Catherine McLean Pirkle associate professor and head of health policy and management specialization}

At a time when everyday life is so deeply impacted by the pandemic (lost jobs, adult children moving back home, schools opening and closing), when tens of millions have been ill and hundreds of thousands have died, and when the news media continuously covers every detail of all things coronavirus disease 2019 (covid-19), it can be hard to recognize that much of normal life continues. This includes childbirth. Clinicians still manage the pregnancies and deliveries of millions of women around the world, some of whom also have the virus.

Although pregnant women are considered a clinically vulnerable group in the United Kingdom ${ }^{1}$ and elsewhere, ${ }^{2}$ it is unclear what, if any, additional risks are associated with covid-19 infection during pregnancy. This uncertainty creates challenges for the care of women during pregnancy and delivery. In the linked systematic review, Allotey and colleagues (doi:10.1136/bmj.m3320) provide insights to guide healthcare providers caring for pregnant women with suspected or confirmed covid-19. ${ }^{3}$

The authors document the clinical manifestations of covid-19 among pregnant women versus non-pregnant women of reproductive age. They also identify risk factors for complications during pregnancy and delivery that might be associated with covid-19 infection and report adverse outcomes for mothers and infants.

To identify articles to review, the authors exhaustively combed through most major medical databases, as well as the vast array of non-peer-reviewed reports on covid-19. From these, they selected 77 studies containing results on a variety of outcomes from which they could synthesize findings to inform clinical practice. This is a living systematic review, meaning that results will be periodically updated as more research accumulates.

One of the more interesting findings was a $7 \%$ positivity rate among women universally screened for covid-19 during pregnancy. Three quarters of these women were asymptomatic. The increased positivity rates in this review reflect the preponderance of studies from the initial massive outbreak in New York City. Although it is unlikely that nearly $10 \%$ of pregnant women have covid-19 at any given moment, such an estimate might be realistic during large outbreaks. Irrespective, it highlights the importance of universal screening during pregnancy to provide appropriate care for infected women and their families, and to protect non-infected women and healthcare staff.

In the systematic review, mortality due to covid-19 was low among pregnant women (0.001\%). As most of the covid-19 related deaths occur among older adults, the low mortality is perhaps unsurprising, given the younger age of most pregnant women. The authors noted differences in the clinical manifestations of the disease in pregnant versus similarly aged non-pregnant women with covid-19. Fever and myalgia were less common. These differences are also unsurprising. Because of the high frequency of covid-19 screening among pregnant women, a large proportion of asymptomatic individuals are captured who do not have classic symptoms of infection.

The study also reported an increased likelihood of admission to the intensive care unit (odds ratio 1.62, $95 \%$ confidence interval 1.33 to 1.96$)$ and need for invasive ventilation (1.88, 1.36 to 2.60$)$ among pregnant women compared with non-pregnant women with covid-19. These associations were even stronger when comparing pregnant women with covid-19 to those without the disease, especially for admission to the intensive care unit. Although based on a limited number of studies-four comparing pregnant to non-pregnant women with covid-19 and only one comparing pregnant women with and without covid-19-these findings are still worrying and underscore the need for careful management of covid-19 during pregnancy.

Finally, the authors assert that "The odds of any preterm birth (3.01, 95\% confidence interval 1.16 to 7.85) was high in pregnant women with covid-19 compared with those without the disease." This result warrants caution, as it is based on only two studies 45 with a cumulative sample size of 339 and only 25 preterm births. The odds ratio mentioned is attributable to only one of the two studies. ${ }^{4}$ This study, conducted in Wuhan, China, early in the pandemic (during its lockdown, in late January through February 2020), compared delivery outcomes of pregnant women with covid-19 related pneumonia with those of two control groups randomly selected from patient medical records in 2019-20.

Consequently, all that should be concluded about preterm birth is that one small study found an association among very ill women, during a stressful lockdown, early in the pandemic. Even if causal, it is unknown if preterm birth is associated with severe covid-19 illness or if predisposing factors contributed to both covid-19 severity and preterm birth.

Overall, the living systematic review by Allotey and colleagues is comprehensive and exhaustive. Limitations largely reflect the state of the current literature and highlight important areas for improved research. As the authors note, there is insufficient research comparing pregnancy outcomes for those with and without covid-19. As is the case with nearly all research on covid-19, the specialty is rapidly 
evolving and findings presented in this review might change as better and larger studies are published.

Competing interests: The BMJ has judged that there are no disqualifying financial ties to commercial companies. The author declares no competing interests.

Provenance and peer review: Commissioned; not peer reviewed.

1 Cabinet Office Guidance. Staying alert and safe (social distancing). Coronavirus (COVID-19) Guidance and support. Updated 13 August 2020. https://www.gov.uk/government/publications/staying-alert-and-safe-social-distancing/staying-alert-and-safe-social-distancing-after-4july (Accessed 4 September 2020)

2 Centers for Disease Control and Prevention. Other people who need extra precautions. Updated 21 July 2020. https://www.cdc.gov/coronavirus/2019-ncov/need-extra-precautions/other-at-riskpopulations.html (Accessed 4 September 2020)

3 Allotey J, Stallings E, Bonet M, etalfor PregCOV-19 Living Systematic Review Consortium. Clinical manifestations, risk factors, and maternal and perinatal outcomes of coronavirus disease 2019 in pregnancy: living systematic review and meta-analysis. BMJ 2020;370:m3320. doi: 10.1136/bmi.m3320 pmid: 32873575

4 Li N, Han L, Peng M, etal. Maternal and neonatal outcomes of pregnant women with COVID-19 pneumonia: a case-control study. Clin Infect Dis 2020;. doi: 10.1093/cid/ciaa352 pmid: 32249918

5 Liao J, He X, Gong Q, Yang L, Zhou C, Li J. Analysis of vaginal delivery outcomes among pregnant women in Wuhan, China during the COVID-19 pandemic. Int J Gynaecol Obstet 2020;150:53-7. doi: 10.1002/ijgo.13188 pmid: 32350871

This article is made freely available for use in accordance with BMJ's website terms and conditions for the duration of the covid-19 pandemic or until otherwise determined by BMI. You may use, download and print the article for any lawful, non-commercial purpose (including text and data mining) provided that all copyright notices and trade marks are retained. 